\title{
Equity in science education and disseminations: lessons learned during COVID-19 pandemics
}

\author{
Mohammad Yousefi $^{1}$, Mahraz Abdollahzadeh ${ }^{2}$, and Shirin Moossavi ${ }^{3}$ \\ ${ }^{1}$ Semnan University of Medical Sciences and Health Services \\ ${ }^{2}$ Pasteur Institute of Iran \\ ${ }^{3}$ Tehran University of Medical Sciences
}

July 1, 2020

\begin{abstract}
Scientific activities including university classes, wet lab research activities, fieldwork, and seminars/conferences have been cancelled in response to the ongoing COVID-19 pandemics. While the public health priority was to contain and mitigate the outbreak, the science sector swiftly adopted technologies to stay connected and continue the scientific activities as much as possible. Creativity, ingenuity, and resilience abound in the science community manifested in successful examples of truly global activities such as seminar series and conferences. While these platforms were initially concerned with maintaining the continuum of science education and dissemination, they attracted participants beyond the boundaries of their respective institutions and countries and thereby increased the equity. While the communities and countries are easing the societal restrictions and the scientific community returns to on-site work, it is important to learn the lessons and ensure equity in science education and dissemination moving forward.
\end{abstract}

\section{Introduction}

Scientific activities including university classes, wet lab research activities, fieldwork, and seminars/conferences have been cancelled in the last couple of months in response to the ongoing COVID-19 pandemics. While the public health priority was to contain and mitigate the outbreak, the science sector swiftly adopted technologies to stay connected and continue the scientific activities as much as possible. Creativity, ingenuity, and resilience abound in the science community manifested in successful examples of truly global activities such as seminar series and conferences. While these platforms were initially concerned with maintaining the continuum of science education and dissemination, they attracted participants beyond the boundaries of their respective institutions and countries and thereby increased the equity. While the communities and countries are easing the societal restrictions and the scientific community returns to on-site work, it is important to learn the lessons and ensure equity in science education and dissemination moving forward.

\section{Academic challenges during COVID-19}

The COVID-19 pandemic has significantly impacted the university community with widespread partial or complete institutional shutdowns with disproportionate impact on the students with ongoing coursework and researchers engaged in wet lab experimental research. Anecdotal reports suggest that some researchers lost 1-6 months of their work due to the forced termination of the ongoing experiments, while others found years of work destroyed due to freezer malfunction and delayed notice during the lockdowns (Korbel \& Stegle, 2020).

Challenges of the emergency shift to remote learning 
While students and professors were advised to work from home, new challenges surfaced including lack of availability of a suitable workspace at home and/or having young children; both of which could have negative impacts on the academic progress and productivity (Korbel \& Stegle, 2020). Low socioeconomic status and lack of required hardware for successful completion of the remote learning activities as well as living in a busy or abusive household could also negatively compound the projected negative impacts on the students' ability to productively engage in academic activities (Soland et al., 2020). In a paper commissioned by the Australian government, researchers identified key areas of concern during the pandemic. These include 1) "material divide", lack of access to the resources and infrastructure; 2) "digital divide" or lack of knowledge of online communication platforms; 3) skills divide in terms of the coping and adaptability skills (Centre for International Research on Education Systems (CIRES) and Mitchell Institute, 2020). These challenges equally apply to students and teaching professors. While the universities are going through the uncertain times, it is vital that challenges of online learning is fully taken into account and mitigated especially as many of the institutions are projecting remote learning into the fall semester.

\section{Gender inequality}

It is often argued that COVID-19 shed light on the already existing societal problems such as gender inequality in science (Andersen, Nielsen, Simone, Lewiss, \& Jagsi, 2020; Huang, Gates, Sinatra, \& Barabasi, 2020). In a survey of 880 trainees and professors, women reported lower self-perceived productively (Korbel \& Stegle, 2020) possibly due to higher involvement of women with children and domestic responsibilities (Derrick, Jaeger, Chen, \& Sugimoto, 2019; Jolly et al., 2014). This and lack of access to childcare during the pandemic has resulted in lower productivity of women academics indirectly assessed by the number of preprints published during the pandemic lockdown (Andersen et al., 2020). Thus all together, policymakers should consider gender inequality and inform polices that promote equity. It is highly crucial that the mitigating policies for loss of productivity ensure gender equity especially for academic mothers (Malisch et al., 2020; Staniscuaski et al., 2020).

\section{Mental health challenges}

Mitigating public health measures towards COVID-19 resulted in widespread mental health issues in individuals working remotely and having less social interactions with family and friends (2020). University students are particularly in danger of adverse psychological impacts during the crisis and in the face of unprecedented uncertainties regarding their ongoing coursework, research, and graduations. This resulted in difficulty in coping and increased rate of mental health issues such as anxiety and depression (Odriozola-Gonzalez, Planchuelo-Gomez, Irurtia, \& de Luis-Garcia, 2020). Therefore, addressing mental health of the students by developing comprehensive psychological crisis interventions are recommended (Y. Bao, Sun, Meng, Shi, \& $\mathrm{Lu}, 2020)$. Preliminary evidence suggest that higher exposure to the social media "infodemic" can exacerbate the psychological impact of COVID-19 (Gao et al., 2020; Zarocostas, 2020) and thus timely and open communications is required at all levels of university administration. Self-isolation during the pandemic can compound the psychological distress of the students. A secondary school principal in China has opted to be optimistic and while shutting down the school to stop spreading SARS-CoV-2, worked hard to spread smiles (Leland, 2020). University presidents and faculty deans have intuitively adopted this compassionate strategy across the globe. Although, professors seem to experience lower rates of negative physiological impacts due to COVID-19 (Odriozola-Gonzalez et al., 2020), they are equally faced with uncertainties. This is especially true for early career investigators who might be more severely impacted by the disruption of their scientific work and unavailability of funds for non-COVID related projects. Given the unprecedented nature of events, extraordinary measures should be put in place to ensure physical and mental well-being of students and professors while alleviating any potential negative career impacted in the long-term.

\section{Equity in performance assessment}

While online education has been an option for some programs and courses before, during the COVID-19 pandemic and shutdown of entire institutions, the pandemic has forced many institutions to offer online education without proper planning. This shift was not easy and presented challenges to both the instructors and 
the students. While the academic activities could continue, many universities recognised the stressful transitions and sub-optimal situation for everyone involved. Consequently, some universities such as University of Manitoba have relaxed grading for the ongoing courses allowing late withdrawal without penalty. Additionally the following explanation was added to the transcripts: "Due to the possible impact of the COVID-19 pandemic on academic performance, students in Winter 2020 were given the option to retain their original grade, exclude their grade from GPA calculations (grades marked with an *), convert their letter grade to Pass $\left(\mathrm{P}^{*}\right)$ or Voluntarily Withdraw (VW) from the course". Similar measure was also taken by the USA National Board of Medical Examiners shifting from numeric score to pass/fail grade for students taking the United States Medical Licensing Examination (USMLE) Step 1 (Whelan, 2020). The impact on ongoing research of graduate students and professors is more considerable as most non-COVID-19-related research activities were halted as a direct consequences of the lockdowns (Nassisi et al., 2020). While researchers are encouraged to engage in other activities such as writing review papers and/or planning future experiments, it is critically important that their performance assessment considers these exceptional circumstances.

\section{Equity in science education}

Equity in education refers to equitable distribution of educational resources and emphasizes both equity in opportunities and equity in educational outcome (Opheim, 2004). While the topic of equity in education is very broad and beyond the scope of this work, examples of online science education activities during COVID19 lockdowns resulted in a more widespread access to education material, which would have been otherwise limited to members of one institution. For example, the Harvard University Microbial Sciences Initiative organised the annual symposium online and open to everyone from around the world or the Microbiome Data Congress initially planned to be held in Toronto moved online, considerably increasing the participation above expectations. Interestingly, many pay-walled publications are now freely available such as like Oxford University Press, Digital Public Library of America (DPLA), and MIT Press eBooks (Lowrie). While these are commendable activities, we need to ensure continued accessibility to the scientific body of knowledge beyond the COVID-19 pandemics.

\section{Attributes of successful online learners and educators}

During the university shutdown, many of the in-person classes switched to online platforms, while instructors and students were both undergoing a steep adjustment curve. It is well-known that students have different learning styles which should be taken into account by instructors (Zapalska \& Brozik, 2006). This is even more important in the online setting where there is limited direct teacher-student interactions (Wang, Hinn, \& Kanfer, 2001; Zapalska \& Brozik, 2006). Zapalska and Brozik(Zapalska \& Brozik, 2006) provide useful tools including presenting the course material in multiple formats, creating a project-based collaborative class environment, and encouraging small group discussion using breakout rooms on zoom (Zapalska \& Brozik, 2006).

The International Society for Technology in Education (ISTE) has provided specific recommendations on maximising the effect of remote learning (Snelling \& Fingal, 2020). These suggestions emphasize equity and include educating the professors for online teaching, rapid online feedback about the quality of online classes and communicating expectations clearly with students, and providing students-centred learning and considering different learning styles (Morgan, 2020; Snelling \& Fingal, 2020). ISTE defines characteristics as requirements for being a successful online learner and teacher. A successful online learner is 1) an empowered learner who can use multiple available technologies to their advantage, 2) a digital citizen fully aware of their digital rights and responsibilities, 3) a knowledge constructor capable of constructing an effective learning experience, 4) an innovative designer who can weave creativity in the use of technology platforms, 5) a computational thinker cultivating the analytical skills, 6) a creative online communicator, and finally 7) a global collaborator allowing cross-cultural interactions (Education, 2016). Similar characteristics have been proposed for successful online educators including being 1) a learner to constantly improving their technology skills, 2) a leader to actively improve the online learning experience, 3) a citizen encouraging responsible participation in the digital world by the students, 4) a collaborator with students and other educators, 5) a designer to create an authentic learning experience, 6) a facilitator supporting students learning endeavours, 
and finally 9) an analyst using data-driven approaches to education (Education, 2017).

Strategies to shift to effective online education during the pandemic

Preliminary reports suggest that students had an overall positive experienced with online education during the COVID-19 lockdowns (Agarwal \& Kaushik, 2020). The personal experience of authors in attending workshops has been very positive. For example, an interactive workshop on introduction to microbiome $16 \mathrm{~S}$ rRNA analysis workshop proved to be uniquely informative because of the screen sharing option whenever a trainee encountered problems. Breakout room option available on Zoom provides a great way for addressing individual trainees' problems. Bao (W. Bao, 2020) summarises strategies successfully adopted at the Peking University to shift all the courses online. The instructor should anticipate and prepare for unexpected online platform shutdown due to user overload. They should avoid overwhelming the students with new information and as much as possible, should divide the lesson into small modules. Due to the limited scope of online interaction including restricted appreciation of body language and facial expression in the online platform, the instructor should attempt to use their voice effectively and speak more slowly. Technologically savvy teaching assistants could greatly facilitate an online teaching session. The successful online learning depends to a large extent on the student's learning activities beyond the online classroom. Therefore, the instructors are advised to enhance motivation of the students by designing engaging assignment (W. Bao, 2020).

\section{Equity in science communication and dissemination}

Communication is the cornerstone of scientific activities. Science communication refers to active engagement in disseminating knowledge to various stakeholders including scientists, industry, policy makers, and general public. Among scientists, science is communicated and disseminated mainly through research publications, seminars, and conferences. Equitable access to the latest developments in the field is a major pre-requisite of successful science careers. Equity in science communication encompasses inclusive activities reaching to a wide range of participants with different cultural identities and life experiences (Canfield et al., 2020). Current practices require critical evaluation to move towards inclusive science communication practices (Amaro \& Mulholland, 2020; Cosgriff, Ebner, \& Celi, 2020; Dawson, 2014; Polk \& Diver, 2020). Traditionally, seminars and conferences are localised to institutions and the publications are behind pay walls significantly diminishing accessibility. However, during the COVID-19 pandemics, traditional means of science communication were transformed overnight providing significantly more equitable access to the public funded research output.

COVID-19 has revolutionised and democratised publication of new scientific findings with the main objective of solving an immediate health challenge affecting the humankind (Kupferschmidt, 2020). Of note, individual success and corporate profits were completely removed as a factor in science communication. This is evident in the recognition of the need and international agreements to share the interim result, genome sequences, molecular simulations, and findings freely and quickly (Amaro \& Mulholland, 2020; Wellcome Trust UK). According to the guidelines, scientists agreed to rapidly and widely share interim and final results with scientific community, make the findings rapidly available on preprint servers such as arXiv, bioRxiv, ChemRxiv, and psyarxiv and publish open access. Crucially, open science framework was promoted to ensure equity and reproducibility (Amaro \& Mulholland, 2020; Korbel \& Stegle, 2020; Wellcome Trust UK). Additionally, several collaborative platforms such as European COVID-19 Data Portal, Crowdfight COVID-19, or data against COVID-19 were developed to connect experts from different fields in a truly cross-disciplinary way. Timely and honest science communication to policy makers and the general public is another learning lesson from the COVID-19. The importance of an open dialogue between the scientific community and the policy makers, often neglected in graduate schools, is also being placed center stage (Berger et al., 2019; Robert et al., 2020).

\section{Scientific conferences: virtual yet equitable}

The problems with current format of the scientific conferences are comprehensively enumerated (Sarabipour et al., 2020). Sarabipour and colleagues argue that "the current organization of many conferences leads to practices that exclude researchers on a wide range of factors including, but not limited to, gender, eth- 
nic, socioeconomic, health and geographical backgrounds, and career stage"; while they present a major environmental risk to the planet (Sarabipour et al., 2020). COVID-19 travel restrictions resulted in many conferences to move online. This resulted in a widely appreciated positive impact in enhancing the equity and accessibility to a vast community of researchers with lack of time and resources to attend a conference in-person.

While there are benefits to attending face-to-face meetings and conferences, many of those benefits could also be obtained in a virtual setting. Additionally, a virtual event broadens the number and diversity of the attendees thereby providing a more equitable means of science dissemination (Klaveren, 2010). The cost and time required to attend a conference in-person is a major barrier for trainees and early career investigators (Malloy, 2020). Moreover, even when the funds are available, researchers tend to go to conferences with immediate relevance to their field of work. Providing virtual online platforms in parallel with the in-person meeting will greatly enhance the participation while also reducing the carbon footprint related to air travel (Weissgerber et al., 2020). Several highly successful examples have been held during the COVID-19 lockdown Cognitive Neuroscience Society; The European Academy of Allergy and Clinical Immunology, and American Society of Nutrition annual conference resulting in participation far-exceeding the most optimistic estimates for the in-person event. Crucially, as the scientific endeavour is without border, the science dissemination should also not be limited to borders. Online platforms will considerably increase participation from trainees and scientists in low and middle-income countries and hence moving towards higher equity.

To ensure that graduate students, postdoctoral fellows, and early-career investigators are not disproportionally impacted by cancellation of in-person meetings, the events should move online if feasible and give due recognition to the researchers (Weissgerber et al., 2020). Examples have emerged where the conferences are held via zoom, pre-recorded talks, and live-streaming on YouTube. To ensure an efficient and authentic experience in virtual events, it is recommended to provide instructions on how to navigate the online platform; allocate time and space for informal networking; and create an environment where the participants can enjoy the complete experience of the conference (Klaveren, 2010).

\section{Conclusion}

While COVID-19 disrupted the academic life at an unprecedented level, it exposed existing inequalities in science education and dissemination. On the other hand, the resilience and ingenuity of the scientific community resulted in a rapid and efficient shift to online platforms resulting in reaching a wider audience

and thereby enhancing equity in science education and dissemination. Moving forward, we need to learn lessons from the COVID-19 pandemic to ensure an equitable academic environment.

Conflict of interest: The authors declare no conflict of interest.

Author contribution: Mohammad Yousefi \& Mahraz Abdollahzadeh: Writing-original draft (equal); Shirin Moossavi: Conceptualization; writing-original draft; writing review \& editing.

\section{References}

Agarwal, S., \& Kaushik, J. S. (2020). Student's Perception of Online Learning during COVID Pandemic. Indian J Pediatr, 87 (7), 554. doi:10.1007/s12098-020-03327-7

Amaro, R., \& Mulholland, A. (2020). A Community Letter Regarding Sharing Biomolecular Simulation Data for COVID-19. J. Chem. Inf. Model., 60 , 2653-2656. doi:10.1021/acs.jcim.0c00319

Andersen, J. P., Nielsen, M. W., Simone, N. L., Lewiss, R. E., \& Jagsi, R. (2020). Meta-Research: COVID-19 medical papers have fewer women first authors than expected. arXiv , 2005.06303v06302

Bao, W. (2020). COVID-19 and online teaching in higher education: A case study of Peking University. Hum Behav Emerg Technol, 2 (2), 113-115. doi:10.1002/hbe2.191 
Bao, Y., Sun, Y., Meng, S., Shi, J., \& Lu, L. (2020). 2019-nCoV epidemic: address mental health care to empower society. Lancet, 395 (10224), e37-e38.

Berger, K. M., Wood, J. L. N., Jenkins, B., Olsen, J., Morse, S. S., Gresham, L., . . . Hayman, D. T. S. (2019). Policy and Science for Global Health Security: Shaping the Course of International Health. Tropical medicine and infectious disease, 4 (2), 60. doi:10.3390/tropicalmed4020060

Canfield, K. N., Menezes, S., Matsuda, S. B., Moore, A., Mosley Austin, A. N., Dewsbury, B. M., . . . Taylor, C. (2020). Science Communication Demands a Critical Approach That Centers Inclusion, Equity, and Intersectionality. Front Commun, 5 , doi: 10.3389/fcomm.2020.00002

Centre for International Research on Education Systems (CIRES) and Mitchell Institute, V. U. (2020). Impact of learning from home on educational outcomes for disadvantaged children . Retrieved from https://www.dese.gov.au/document/professor-stephen-lamb-centre-international-researcheducation-systems.

Cosgriff, C. V., Ebner, D. K., \& Celi, L. A. (2020). Data sharing in the era of COVID-19. The Lancet. Digital health, 2 (5), e224-e224. doi:10.1016/S2589-7500(20)30082-0

Dawson, E. (2014). Reframing social exclusion from science communication: moving away from 'barriers' towards a more complex perspective. J Sci Commun, 13 , C02.

Derrick, G. E., Jaeger, A., Chen, P.-Y., \& Sugimoto, C. R. (2019). Models of parenting and its effect on academic productivity: Preliminary results from an international survey. In: Proceedings of the 17th International Conference on Scientometrics $\&$ Infometrics. International Society for Informetrics and Scientometrics, ITA, pp. 1670-1676.

Gao, J., Zheng, P., Jia, Y., Chen, H., Mao, Y., Chen, S., . . . Dai, J. (2020). Mental health problems and social media exposure during COVID-19 outbreak. PLoS One, 15 (4), e0231924.

Huang, J., Gates, A., Sinatra, R., \& Barabasi, A.-L. (2020). Historical comparison of gender inequality in scientific careers across countries and disciplines. Proc Natl Acad Sci USA, 117, 201914221. doi:10.1073/pnas.1914221117

International Society for Technology in Education. (2016). ISTE standards for students. In. Arlington: VA: International Society for Technology in Education.

International Society for Technology in Education. (2017). ISTE standards for educators. In. Arlington: VA:International Society for Technology in Education.

Jolly, S., Griffith, K. A., DeCastro, R., Stewart, A., Ubel, P., \& Jagsi, R. (2014). Gender differences in time spent on parenting and domestic responsibilities by high-achieving young physician-researchers. Ann Intern Med, 160 (5), 344-353.

Klaveren, F. v. (2010). Will your next poster session be in a virtual world? Biochem (Lond), 32 (3), 42-45. doi:10.1042/BIO03203042

Korbel, J. O., \& Stegle, O. (2020). Effects of the COVID-19 pandemic on life scientists. Genome Biol, 21 (1), 113. doi:10.1186/s13059-020-02031-1

Kupferschmidt, K. (2020). A completely new culture of doing research. Coronavirus outbreak changes how scientists communicate ScienceScience, doi:10.1126/science.abb4761.

Leland, A. (2020). 'Smiles Are Infectious': What a School Principal in China Learned From Going Remote. Navigating Uncertain Times: How Schools Can Cope With Coronavirus. Retrieved from https://www.edsurge.com/news/2020-03-20-smiles-are-infectious-what-a-school-principal-inchina-learned-from-going-remote 
Lowrie, R. (2020). COVID-19 Open Access Resources. Retrieved from https://guides.library.harvard.edu/covidoa

Malisch, J. L., Harris, B. N., Sherrer, S. M., Lewis, K. A., Shepherd, S. L., McCarthy, P. C., . . . Deitloff, J. (2020). Opinion: In the wake of COVID-19, academia needs new solutions to ensure gender equity.Proc Natl Acad Sci USA, doi 10.1073/pnas.2010636117. doi:10.1073/pnas.2010636117

Malloy, J. (2020). Stop making graduate students pay up front for conferences. Nature , doi: 10.1038/d4158641020-00421-w.

Morgan, H. (2020). Best Practices for Implementing Remote Learning during a Pandemic. The Clearing House: A Journal of Educational Strategies, Issues and Ideas, 93 (3), 134-140.

Nassisi, M., Audo, I., Zeitz, C., Varin, J., Wohlschlegel, J., Smirnov, V., . . . Sahel, J.-A. (2020). Impact of the COVID-19 lockdown on basic science research in ophthalmology: the experience of a highly specialized research facility in France. Eye, 34, 1187-1188.

Odriozola-Gonzalez, P., Planchuelo-Gomez, A., Irurtia, M. J., \& de Luis-Garcia, R. (2020). Psychological effects of the COVID-19 outbreak and lockdown among students and workers of a Spanish university.Psychiatry Res, 290 , doi:10.1016/j.psychres.2020.113108. doi:10.1016/j.psychres.2020.113108

Opheim, V. (2004). Equity in education: country analytical report Norway. Retrieved from https://www.oecd.org/norway/38692818.pdf

Plomecka, M. B., Gobbi, S., Neckels, R., Radziński, P., Skórko, B., Lazerri, S., . . . Jawaid, A. (2020). Mental Health Impact of COVID-19: A global study of risk and resilience factors. medRxiv , 2020.2005.2005.20092023. doi:10.1101/2020.05.05.20092023.this

Polk, E., \& Diver, S. (2020). Situating the Scientist: Creating Inclusive Science Communication Through Equity Framing and Environmental Justice. Front Commun, 5, 6.

Robert, D., Ford, A. T., Moehring, A. J., Kaida, A., Krishnaswamy, A., Mah, C. L., . . Crooks, V. A. (2020). Politicians and scientists need strong connections during the coronavirus crisis - and beyond. Retrieved from https://theconversation.com/politicians-and-scientists-need-strong-connections-during-thecoronavirus-crisis-and-beyond-136482

Sarabipour, S., Schwessinger, B., Mumoki, F. N., Mwakilili, A. D., Khan, A., Debat, H. J., . . . Mestrovic, T. (2020). Evaluating features of scientific conferences: A call for improvements. BioRxiv , 2020.2004.2002.022079. doi:10.1101/2020.04.02.022079

Snelling, J., \& Fingal, D. (2020). 10 strategies for online learning during a coronavirus outbreak. Retrieved from https://www.iste.org/explore/learning-during-covid-19/10-strategies-online-learning-duringcoronavirus-outbreak

Soland, J., Kuhfeld, M., Tarasawa, B., Johnson, A., Ruzek, E., \& Liu, J. (2020). The impact of COVID-19 on student achievement and what it may mean for educators. Brown Center Chalkboard Retrieved from https://www.brookings.edu/blog/brown-center-chalkboard/2020/05/27/the-impact-of-covid19-on-student-achievement-and-what-it-may-mean-for-educators/

Staniscuaski, F., Reichert, F., Werneck, F. P., de Oliveira, L., Mello-Carpes, P. B., Soletti, R. C., . . . Parent in Science, M. (2020). Impact of COVID-19 on academic mothers. Science, 368 (6492), 724. doi:10.1126/science.abc2740

Wang, X. C., Hinn, D. M., \& Kanfer, A. G. (2001). Potential of computer-supported collaborative learning for learners with different learning styles. J Res Technol Edu, 34 (1), 75-85.

Weissgerber, T., Bediako, Y., de Winde, C. M., Ebrahimi, H., Fernandez-Chiappe, F., Ilangovan, V., . . . Tay, A. (2020). Mitigating the impact of conference and travel cancellations on researchers' futures. Elife, 9 , e57032. doi:10.7554/eLife.57032 
Wellcome Trust UK. Sharing research data and findings relevant to the novel coronavirus (COVID-19) outbreak [Press release]. Retrieved from https://wellcome.ac.uk/coronavirus-covid-19/open-data

Whelan, A. J. (2020). The Change to Pass/Fail Scoring for Step 1 in the Context of COVID-19: Implications for the Transition to Residency Process. Acad Med, doi: 10.1097/ACM.0000000000003449.

Zapalska, A., \& Brozik, D. (2006). Learning styles and online education. Campus-Wide Information Systems, 23 , 325-335.

Zarocostas, J. (2020). How to fight an infodemic. Lancet, 395 (10225), 676. doi:10.1016/s0140-6736(20)30461-

$\mathrm{x}$ 